\title{
Role of Smart Applications for Teaching Mathematics at Government School in Oman
}

\author{
Jomana Saif Mahfudhi \\ Juhaina Al Raisi \\ Vikas Rao Naidu \\ Bushra Al Kalbani \\ Rajani Rani Gupta
}

\author{
Middle East College \\ Middle East College \\ MIDDLE EAST COLLEGE \\ Middle East College \\ Middle East College
}

\begin{abstract}
Education technology is important for every educational organization in these days. With the advancement in smart technology and Wi-fi enabled campus, it is possible to implement various online and e-learning tools to support the educational content in order to enhance teaching and learning experience. This research aims to apply such technology into practice at the primary school level, where the teachers will be able to customize or develop their own applications using some freely available resources. This will facilitate an understanding of mathematics through customized user experience and even a teacher with minimal knowledge of computer will be able to make use of technology to make the mathematics class more interesting. This research collected data from different sources such as questionnaires and interviews. The authors found from the data that majority of the participants strongly agreed that such e-learning system was greatly beneficial, especially, for the abstract subjects such as mathematics.
\end{abstract}

\section{Introduction}

School is an institution set up by a government to prepare new generation members to work for the future market and society's demand. At school, teachers teach, educate, and prepare society members for the future. The school is important in the lives of students because it is very important in integrating students with each other in one environment.

Technology has become a big part of everyone's life. This research paper suggests educational project for mathematics units by means of modern techniques and technology. Basic objectives of the proposed research involve:

- Saving the time and effort.

- Developing the way of education.

- Overcoming difficulties.

The data relevant to the project is collected from various different sources such as websites, article, e-books, and books. A meeting with mathematics teachers was held. Their response was very encouraging as they also found that the idea of incorporating technology in teaching mathematics will be very useful to teach mathematics and this may lead to more student engagement.

Project management is proficiency that is required at the planning stage to identify the required tools, skills and project activities. The main objective of any project is to achieve the objective of the project. The success of any project is based on the achievement of initially planned goals. Any project is defined through its benefits and outputs. Authors have gone through a book on project management by Michael. This book supported this project by identifying the risks involved within a project and provided corrective measures to overcome the involved risks at the implementation 


\section{Journal of Student Research}

Fourth Middle East College Student Research Conference, Muscat, Sultanate of Oman

stage. (Michael W, 2015)

The success of any project is measured upon achieving the planned target and its completion within the assigned budget. The main components of Project Management are:

- Identifying the project requirements.

- Recognizing a plan to manage and achieve the project.

- Categorizing the risks and solutions to encode them.

- Determining the reasons for success of the legislator according to the project plan.

To understand this in detail, authors have referred a book by Harold Kerzner (2017). This book specializes in the management of software products. The book contains information about project planning and management. This book helps us to manage this project and identify the current project requirements and feasibility. This book supports the reader by defining the project management, ways to complete the project as per the set timelines and hence build confidence in project management.

As developing this application requires the knowledge of user interface and design principles, we gone through another book by Ryan Cohen (2014). This book explains the design of the user interface for Android applications. The book is ideal for the designers of mobile phone application as it aids the designers about the brief concepts required for the development of the application. The authors of this book have also introduced the principles which must be learned in application design and user interface design for Android applications (Ryan Cohen, 2014).

Another book by Hagos (2018) was found useful as it specialized in teaching Android Studio software. This book enabled us to learn about the latest tools, most productive aspects in the Android system and best practices for the development of Android applications. In addition to this, the book by Aliferi_2017 explains the codes for developing and lay outing the design. (Aliferi, 2017).

Authors also studied various use of mobile phone applications in education and learning processes. The purpose of this paper is to identify the benefits and hitches of using mobile application in teaching mathematics. The study is supported by the data collected through questionnaires and interviews of various students about the use of mobile phones. The results of the study showed that students prefer to use mobile phones in education. Also, students informed that they understand and learn the concepts faster with the applications as compared to the traditional education.

Many researchers did investigation in this area. Bushra et. Al (2018) used a mobile application for teaching mathematics to the students of Middle East College, one of the leading Higher Education Institutions in Oman. This application supported students and provided a platform where students can interact with each other beyond the class contact hours. The educational applications of mathematics have spread widely both in mobile phone and online education. Teachers are incorporating the use of online lessons in mathematics modules by using computers with tablet interfaces in lectures rather than using a blackboard or projector (Drigas, 2015).

The study explains that the mobile device has become a common thing for people nowadays due to its ease of communication. Mobile phone allows people to communicate, work and play. Hence, the use of mobile phone can be expanded into learning. Use of technology in teaching mathematics incorporate fun and play into education. To do this many educational games were developed.

Motivating students in class plays a significant role in teaching and learning. Another important task is to adopt a proper teaching method as per the level of students. Using a teaching method which involves student participation is very crucial in teaching mathematics to ensure the progress 


\section{Journal of Student Research}

Fourth Middle East College Student Research Conference, Muscat, Sultanate of Oman

of educational process. This method is selected due to the aim of the subject and its learning outcome. In addition to this, this will facilitated the needs of the individual students and teachers. It also inform the implementation of appropriate teaching method such as, motivating students, using modern method in teaching, collaborative learning, interactive learning environment, and using the technology (Alzbeta \& Emese, 2016).

The technology plays an important role in education, especially in the learning of subject such as mathematics, which need guidance at several stages. So, mixing technology into the mathematics classroom is more effective as some of studies implied that the linking e-tools, teaching pedagogies and curriculum would not only equip them with better understanding of mathematics, but also prepare them for future learning. Thomas E. Hodges and Elizabeth Conner in their article illustrated the role of teacher and students in a Mathematics classroom which includes technology. (Thomas E. \& Elizabeth, 2011)

There will be many challenges in adopting the technology in the school classes. One of the major challenge is the availability of WIFI, as schools, in general, have less facilities compared to the universities and colleges. Also students are not allowed to make use of mobile phone inside the classrooms. This is the major reason that the instructors are using the traditional way of transferring the information by using whiteboard. To overcome this shortcoming, some studies suggested that the traditional classrooms can be more active if teachers enhance the learning by making the interactive learning supported by whiteboard (Karen \& Rachel, 2010). Authors agreed that the resources such as, a lesson plan, practical skill will be helping the teacher to easily transfer the information and test students' knowledge as per the curriculum, meeting the standards and level set by the University and the Government.

Using Mobile online Apps in Mathematics has spread widely for the purpose of educational need. It is incorporated in lesson plans by most of mathematics teacher to equip students with better understanding of the mathematical topics and various complex mathematical problems. Some of the teachers are taking mathematics classes by using graphics tablet for conducting the lectures instead of using the Whiteboard (Athanasios \& Marios, 2015).

In $21^{\text {st }}$ century, technology can help in facilitating learning at each and every level. Also, anyone can use it everywhere and anywhere. In addition, some of applications are offline; people can download them in any device such as computer, laptops and mobile devices. Some of these applications are helping for the students to understand the concept of mathematics (Fengfeng_2008).

First, the teacher must be more qualified enough in using the e-tool in any classroom. Mathematics concept challenges students to apply their knowledge in real life and teacher to transfer the information to students who are surface learners. Mathematics teacher should have patience, courage and be more clever in using the software in classroom with more confidence and innovation (Patrick \& Jared_2011). A teacher has options to select ways to deliver the lesson but by ensuring all auditions understand and receive the lesson. Also, the teacher needs to look at students' behavior and ability to understand as some of them are deep learners and other are surface learners.

Using mobile phone apps for purpose of teaching and learning will help students to understand and learn faster rather than using only traditional ways in teaching. Most of researches show the positive result in using e-tool in enhancing and helping the students to be more qualified and able to think. But most of them have shown restrictions of usage of mobile devices in schools compared to higher education institutions (Mohammed A A \& Ala', 2018).

Some mobile phone Apps allow people to communicate with others, work for business, do shopping and play games. But some of these games are more helping for mathematic where educational game combines fun, ply and learning (Norizan, Khaliq, \& Marina, 2010) 


\section{Journal of Student Research}

Fourth Middle East College Student Research Conference, Muscat, Sultanate of Oman

Effective teaching is most important to help the students. So, the teacher must be more collaborative and create interactive class environment. Also, S/he must use the smart technology to facilitate teaching approach. Some of the researchers use the mobile phone to enhance teaching and learning where the result was more positive and effective the student's performance. Using mobile phone for the purpose of teaching, e.g., sharing videos, training, quiz, interactive online activities are much needed for this generation (Bushra, Azahir, Vikas, \& Rajani, 2019)

Project management of mathematics is helping and finding solutions to identify the risks which will be faced in any implementation. Project management is an application preparation for learning any project activities, skills and tool (Godfaurd \& Abdulkadir, April 14-15, 2016). There are four Project Management Components such as determine the reasons for success according to the goal, categorize project requirements, identify a plan to manage and archive the project and classify risks and results to encode them. Management software products book has information about project planning and managements also can help and identify the project requirements and viability. (Harold, 2017)

GUI Design for Android Apps explain an ideal and concise introduction to developers and designer of mobile phone applications. Also, the book explains the design of the user interface for Android applications. In addition, it introduces the principles of applications designs and user interface design for Android applications. (Bao N., Bryan, Ishan, \& Atif, 2013)

Learn Android Studio help to increaser the time of developing android and teach design applications using by using it. Also, it uses the latest tools and the productive in the Android system and greatest practices of the progress of Android applications (Ted, 2018). Android Programming Cookbook is used to explain how to develop and lay out design codes (Ian, 2017).

Gamification is also one of the methods to teach mathematics especially at basic level. It was practiced in one of the elementary schools in Taiwan and shown a very positive result. (Liao \& Chen, 2018)

\section{Data analysis:}
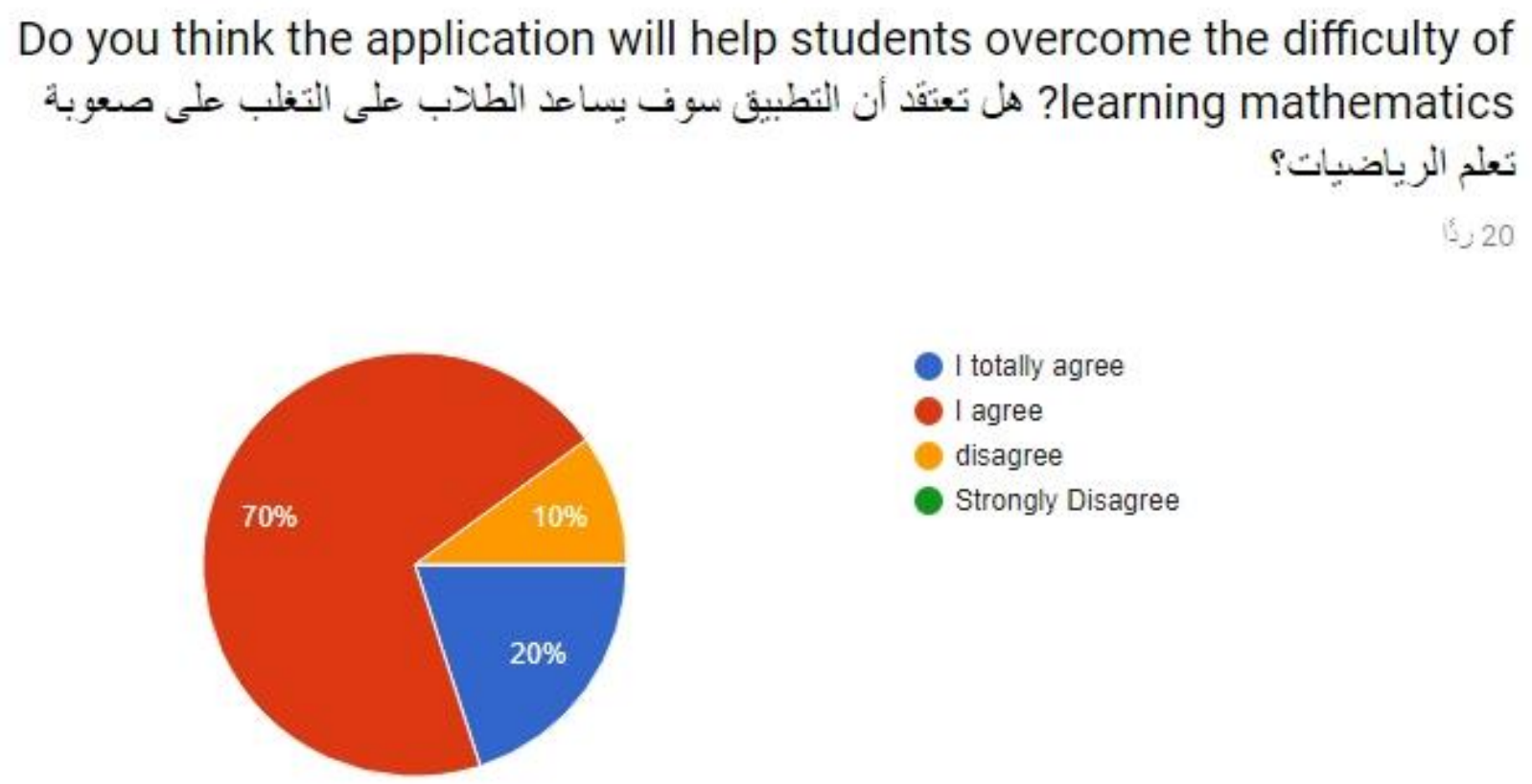

I totally agree

I agree

disagree

Strongly Disagree 


\section{Journal of Student Research}

Figure 1. Analysis chart 1

This diagram examines whether students find it difficult to learn mathematics. The graph shows that most students face $80 \%$ math difficulties. This means that students need modern means to learn mathematics.

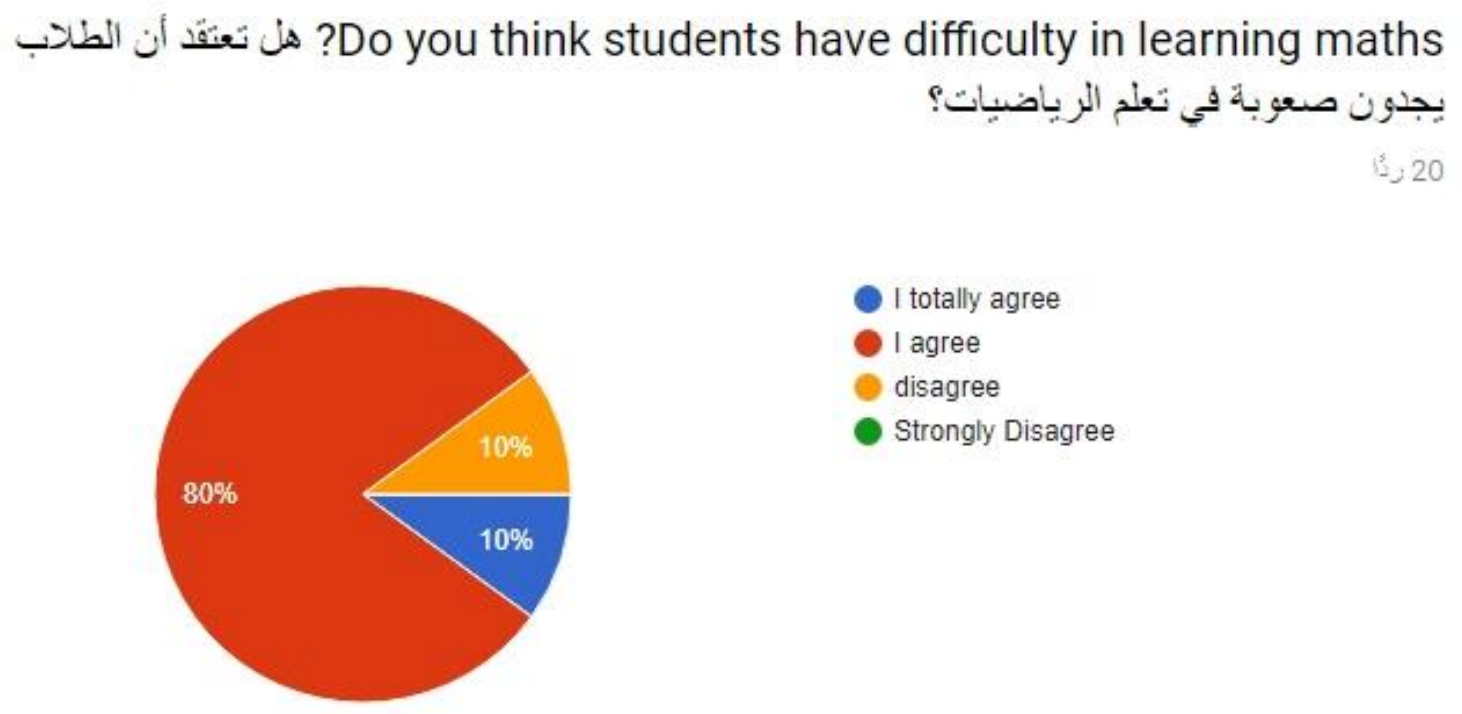

Figure 2. Analysis chart 2

It shows through the graph that most people think that the application will help students to pass math difficulties. The graph shows that students need a $70 \%$ education application. This means that the establishment of this application for this institution will make technology into education.

\section{Do you think the application will help students overcome the difficulty of}

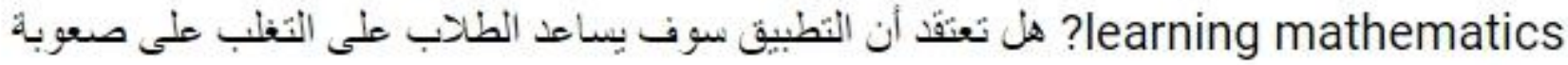

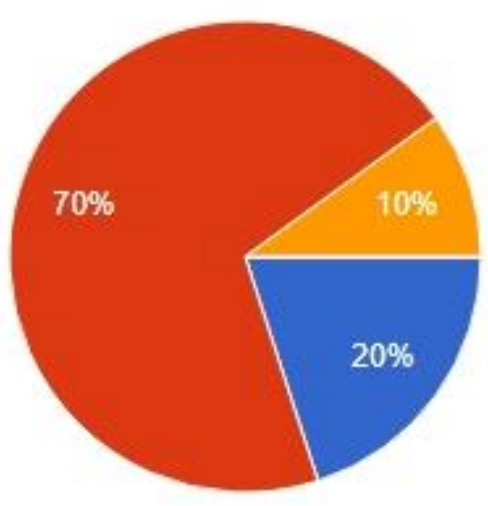


Figure 3. Analysis chart 3

The graph shows that supporters of this application grew by $70 \%$. This means that this application is good for students' education.

\section{Figure 4. Analysis chart 4}

The graph shows that the course of study that students face difficulty in teaching mathematics, the pre-school track by $30 \%$. The least path they face is the preparatory course of $15 \%$. This means that this application was designed for the pre-school stage.

Figure 5. Analysis chart 5

The graph shows that everyone is satisfied with the creation of this application. The application is good and useful for students.

It is concluded from an open question answers that the application is good and useful. The application serves students a lot. People suggested the application contains games and educational songs. Also, the application should serve the pre-school stage. The application contains a section for communication between students and teachers because this facilitates the task of education.

\section{Conclusion:}

I would like to thank God almighty for his Grace to support me in finishing this project plan. The project contains information, project implementation plan and graphics data. The project gave me a lot of information in project management. The project requirements also support the acquisition of knowledge such as: the method of using MS project, planning the project cost, drawing the plans for the application work, identifying the risks facing the project and ways of overcoming the risks.

\section{Acknowledgments:}

The authors would like to express their thanks to Allah Almighty for his abundant blessings because of this research, which took its form. Sincere thanks to family members and friends who have always supported in carrying out these tasks. Finally, from the bottom of the heart, the authors thank the management, staff and friends of Middle East College.

\section{References}

Alzbeta, K., \& Emese, T. (January 2016). USE OF PARTICIPATORY METHODS IN TEACHING AT THE UNIVERSITY. The Online Journal of Science and Technology, 82-90.

Athanasios Drigas, M. P. (2015, nov 3). A Review of Mobile Learning Applications for Mathematics. pp. 1-6.

Athanasios, D., \& Marios, P. (2015). A Review of Mobile Learning Applications for Mathematics. International Journal of Interactive Mobile Technologies, 18-23.

Bao N., N., Bryan, R., Ishan, B., \& Atif, M. (2013). GUITAR: an innovative tool for automated testing of GUI-driven software. Autom Softw Eng (2014), 65-105. 


\section{Journal of Student Research}

Fourth Middle East College Student Research Conference, Muscat, Sultanate of Oman

Bushra, A. K., Azahir, A. S., Vikas, R., \& Rajani, R. (2019). ENCHANGING STUDENT LEARNING IN MATHEMATICS CLASSES BY MEANS OF ONLINE COLLABORATIVE TOOLS. ADVED 2019-5th International Conference on Advances in Education and Social Sciences (pp. 88-94). Istanbul, Turkey: ocerints.org.

Feras, H., \& Motasem, n. (2019). The Impact of Using Educational Software on Student Fraction Achievements Case Study: Economic Course. International Journal of Information Science \& Technology, 2550-5114.

Godfaurd, A. J., \& Abdulkadir, G. (April 14-15, 2016). ACTIVITY THEORY PERSPECTIVE FOR PROJECT MANAGEMENT RESEARCH IN THE BUILT ENVIRONMENT. Fifth International Scientific Conference on Project Management in the Baltic Countries (pp. 104-113). Riga: University of Latvia.

HAROLD, K. (2017). PROJECT MANAGEMENT. Berea, Ohio: John Wiley \& Sons, Inc.

Ian, D. (2017). Android Cookbook PROBLEMS AND SOLUTIONS FOR ANDROID DEVELOPERS. United States of America: O’Reilly Media, Inc.

Karen, M., \& Rachel, S. (2010). Talking about science in interactive whiteboard classrooms. Australasian Journal of ducational Technology, 417-431.

Ke, F. (December 2008). A case study of computer gaming for math: Engaged learning from gameplay? Computers \& Education, 1609-1620.

Liao, u. k., \& Chen, Y. H. (2018). Effects of Integrating Computer Technology into Mathematics Instruction on Elementary Schoolers' Academic Achievement: A meta-analysis of One-hundred and Sixty-four Studies from Taiwan. World Conference on E-Learning in Corporate, Government, Healthcare, and Higher Education, 165-173.

M, D. N. (2010). Discover mathematics on mobile devices using gaming approach. pp. 670-677.

Mohammed A A, F., \& Ala', K.-D. (2018). Using Mobile Phone Applications in Teaching and Learning Process. International Journal of Research in English Education, 48-68.

Norizan, M., Khaliq, M., \& Marina, I. (2010). Discover Mathematics on Mobile Devices using Gaming Approach. International Conference on Mathematics Education Research 2010, 670-677.

Patrick, W., \& Jared, K. (February 2011). Technology Integration Barriers: Urban School Mathematics Teachers Perspectives. Journal of Science Education and Technology, 17-25.

Ted, H. (2018). Learn Android Studio 3: Efficient Android App Development. philippines.

Thomas E., H., \& Elizabeth, C. (February 2011). Reflections on a Technology-Rich Mathematics Classroom. Mathematics Teacher, 432-438.

Using Mobile Phone Applications in Teaching and Learning Process. (2018). pp. 3-2. 